\title{
Correction to: Vitamin D protects endothelial cells from irradiation-induced senescence and apoptosis by modulating MAPK/SirT1 axis
}

\author{
F. Marampon ${ }^{1}$ - G. L. Gravina ${ }^{1}$. C. Festuccia ${ }^{1}$ - V. M. Popov ${ }^{2}$ - A. Colapietro ${ }^{1}$ - P. Sanità ${ }^{1}$ D. Musio ${ }^{3} \cdot$ F. De Felice ${ }^{3}$. \\ A. Lenzi ${ }^{4} \cdot$ E. A. Jannini ${ }^{5} \cdot$ E. Di Cesare ${ }^{1} \cdot$ V. Tombolini $^{3}$
}

Published online: 5 June 2020

(c) Italian Society of Endocrinology (SIE) 2020

\section{Correction to: J Endocrinol Invest (2016) 39:411-422 https://doi.org/10.1007/s40618-015-0381-9}

Unfortunately, the 5th author name has been publisehd incorrectly in the original publication. The complete correct name is given below.

Alessandro Colapietro

Publisher's Note Springer Nature remains neutral with regard to jurisdictional claims in published maps and institutional affiliations.

The original article can be found online at https://doi.org/10.1007/ s40618-015-0381-9.

G. L. Gravina

giovanniluca.gravina@libero.it

1 Division of Radiotherapy and Radiobiology, Department of Biotechnological and Applied Clinical Sciences, University of L'Aquila, L'Aquila, Italy

2 Department of Radiation Oncology, University of Pennsylvania, Philadelphia, PA, USA

3 Department of Radiotherapy, Policlinico Umberto I "Sapienza" University of Rome, Rome, Italy

4 Department Experimental Medicine, "Sapienza" University of Rome, Rome, Italy

5 Department of System Medicine, University of Tor Vergata, 00133 Rome, Italy 